\title{
Parasellar Chondroid Chordoma: a Case Report
}

\author{
Rao BSS ${ }^{1}$, Vissa Shanthi ${ }^{2}$, N Mohan Rao ${ }^{3}$, Bhavna G ${ }^{4}$, Swathi $S^{5}$, Murali Mohan $K^{6}$ \\ ${ }^{1}$ Dr B Syam Sundar Rao, Associate Professor, ${ }^{2}$ Dr Vissa Shanthi, Associate Professor, ${ }^{3}$ Dr N Mohan Rao, Associate \\ professor, ${ }^{4}$ Dr Bhavna G, Assistant Professor, ${ }^{5}$ Dr Swathi S, Assistant Professor, ${ }^{6}$ Dr Murali Mohan K, Professor. All are \\ affiliated with Dept of Pathology, Narayana Medical College, Nellore, AP, India
}

Address for correspondence: Dr. B.Syam Sundar Rao, Email: syam.byna@gmail.com

\begin{abstract}
Chordomas are distinct tumors which arise almost exclusively in the midline skeleton, from skull base to the sacrum. Chondroid chordoma is a rare form of chordoma with features of chordoma and chondrosarcoma arising almost at skull base. We report a case of a right parasellar chondroid chordoma in 54 years old female. Histopathology and IHC confirm the diagnosis of this case.
\end{abstract}

Keywords: Chordoma, Parasellar, Chondrosarcoma.

\section{Introduction}

Chordomas were first described by Virchow in 1857 as tumors made up of physaliferous cells derived from rests of notochord [1]. Chordomas are rare slow growing malignant bone tumors that account for $1 \%$ all malignant bone tumors and 0.1 to $0.2 \%$ intracranial neoplasms $[2,3]$. They rarely metastasize but are locally invasive and recurrences may occur. [4,5]. Men are affected more commonly than woman with male to female ratio $6: 5$ in endocranial chordomas [6].

Chordomas that occur particularly in the sacral region (50\%), spheno occipital region (35\%), and vertebrae (15\%) [7]. Depending on anatomical location and clinical features three types were described which are tumors involving sellar region associated with chiasma compression and hypopituitarism parasellar chordomas characterized by occulomotor nerve palsy, optic tract compression, and hypopituitarism chordomas involving clival region present with cranial nerve paresis and brain stem compression [8].

\section{Case Report}

A 58 years old woman presented with right periorbital pain, double vision and squint for one year. There was no history of dimininution of vision and motor or sensory disturbances. On examination she has right lateral rectus palsy, mild ptosis of right eyelid enophthalmos and miosis.

Manuscript received: $16^{\text {st }}$ July 2014

Reviewed: $20^{\text {th }}$ July 2014

Author Corrected: $16^{\text {th }}$ Aug 2014

Accepted for Publication: $21^{\text {st }}$ Aug 2014
Provisional diagnosis of right para sellar chordoma was made and Magnetic resonance imaging was done. MRI imaging of the brain revealed well defined lobulated heterogenous signal intensity extra axial mass in the right parasellar region with foci of calcifications and fat signal intensity areas within it showing heterogenous enhancement with buckling of right optic nerve with per optic fluid compression of right cavernous sinus displacing the internal cartoid artery and middle cerebral artery, eroding the clivus, extending up the nasopharynx [Fig 1\& 2].

Differential diagnosis of chordoma, teratoma and chondrosarcoma were considered. The tumor was removed through right frontotempoal craniotomy with orbitozygomatic osteotomy, temporopolar extradural transcavernous approach. Tumor tissue was sent to pathology department for histopathological examination. Macroscopic findings showed multiple grey brown bits measuring altogether $2 \mathrm{~cm}$.

Histopathological examination of tissue showed lesion with myxoid areas containing cells with round nuclei and moderate cytoplasm. Few cells have eccentrically placed nuclei. Physaliphorous cells with foam cytoplasm were noted.

Foci of cartilaginous differentiation with chondrocytes were seen. Foci of calcification were also noted [Fig $3 \&$ 4]. IHC was strongly positive for cytokeratin and EMA, there by confirming diagnosis of chondroid chordoma. 


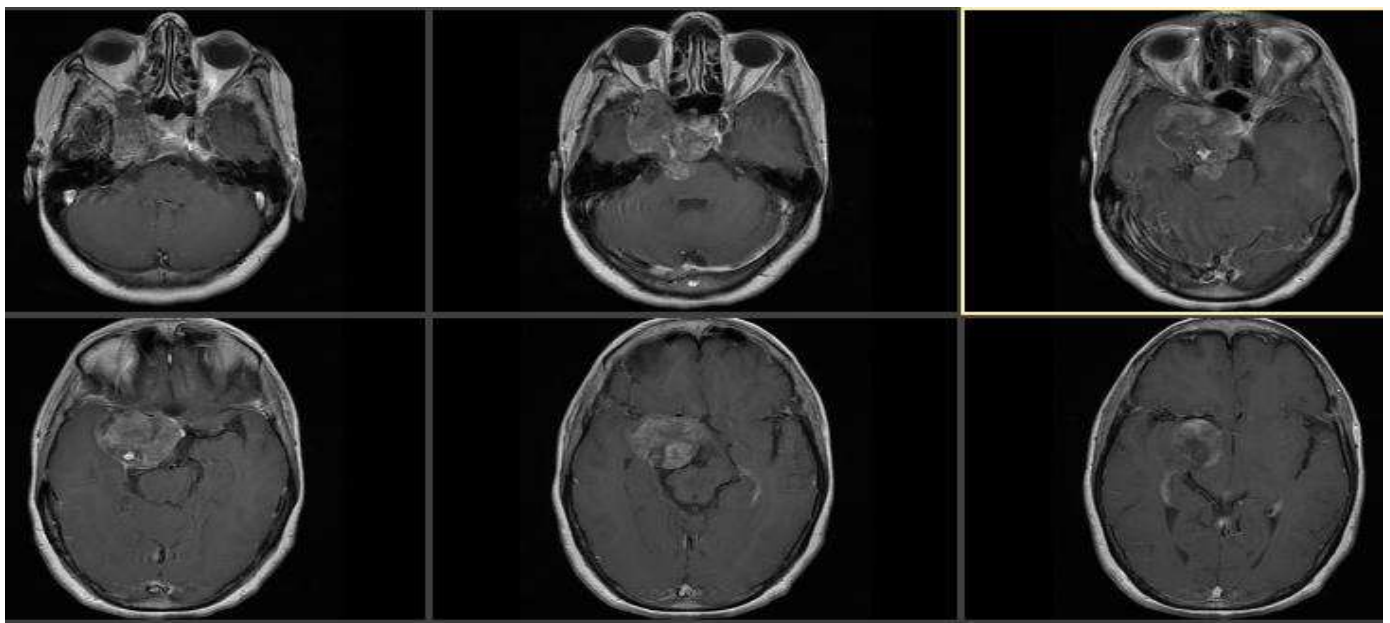

Fig 1: MRI T1W Showing axial plane isointense mass in para sellar region, compressing mid brain \&displacing internal carotid artery.
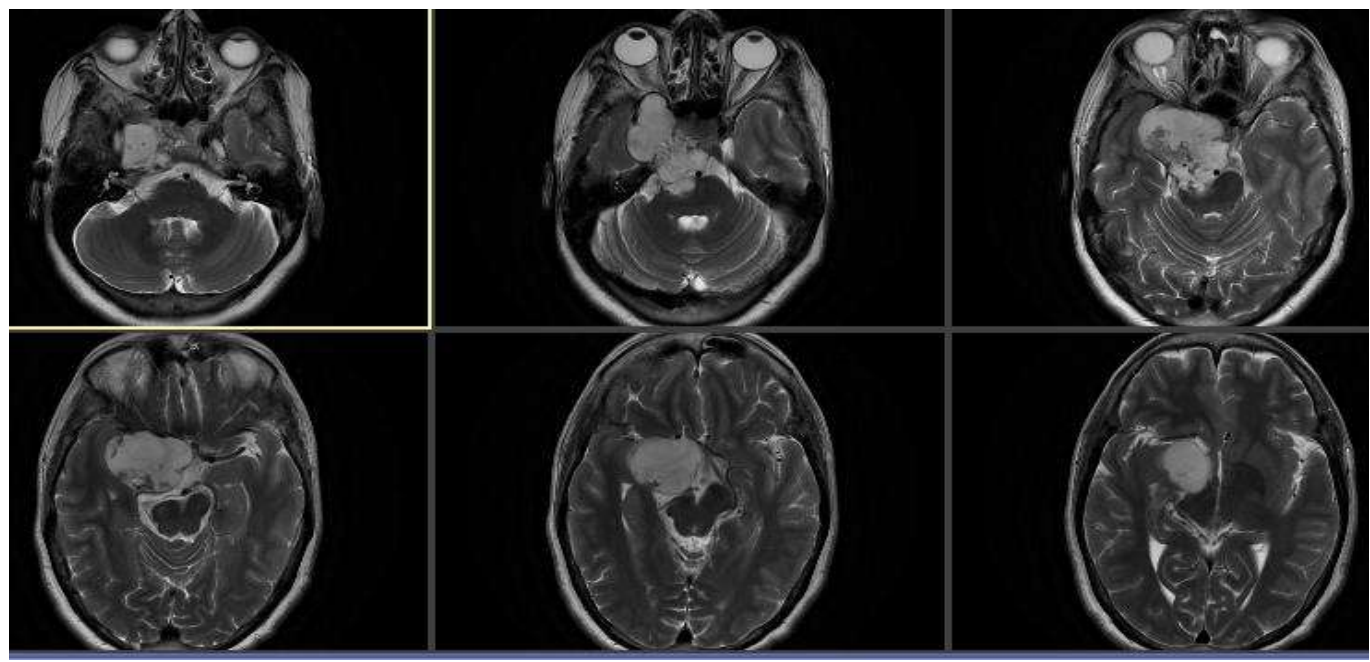

Fig 2: MRI T2W showing hyper intense mass in parasellar region.

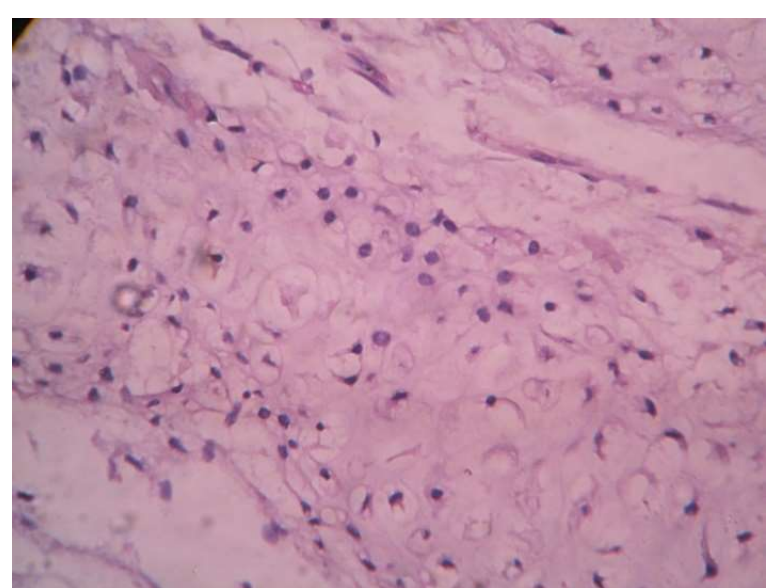

Figure 3: (H\&E,400X) Shows tumor cells having vacuolated cytoplasm with nucleus centrally placed and peripherally placed in some cells (physaliferous cells)



Figure 4: (H\&E,100X) Shows islands of cartilage with degenerating chondrocytes and a few chordoma cells 


\section{Discussion}

Chordomas are thought to be tumors arising from remnants of the embryonic notochord. These are almost always mid line tumors, found along the central axis of the body from the skull base behind the sella and in the clivus, down along the vertebral column to lumbosacral region. Chondroid chordoma is a controversial tumor entity that was originally described by Heffelfinger and colleagues as a biphasic malignant neoplasm possessing elements of both chordoma and cartilaginous tissue [9].

Skull base chordoms tend to present osseous permeation and have a high rate of recurrence [5, 9]. Cranial chordomas are thought to originate from the sphenooccipital synchondrosis and they may spread to sellarparasellar area, posterior fossa and nasophaynx [10]. Radiolological examinations have a definite role in the pre operative diagnosis of this lesion. MRI is better for demonstrating the exact position of brain stem and optic chiasm relative to the tumor and tumor extension in to nasopharynx and cavernous sinus and relationship with carotid, vertebral, basilar arteries [11].

Currently endoscopic surgery opened a new avenue in the management of clival chordomas providing an excellent visualization of clivus and surrounding structures. Surgical procedures and endoscopic surgeries were selected for preservation of vital anatomical structures in the literature [12]. In most cases the complete surgical resection followed by radiation therapy offers the best chance of long term control.

Histologically chordomas are cartilage like tumors consisting of cells arranged in lobular pattern in a diffuse myxoid matrix. The most characteristic cell is the physaliphorous cell that is a medium sized to large cell with a small eccentrically or centrally located nucleus and vacuolated cytoplasm with bubble like appearance. Immunohistochemically the neoplastic cells of chordoma were positive for cytokeratins, epithelial membrance antigen, and vimentin $[13,14,15]$.

The microscopic differential diagnosis of chondroid chordoma is chondro sarcoma. Skull base chondro sarcomas may arise laterally where as chordomas are almost exclusively midline tumors. Histological chondrosarcoma shows sheets of hyaline cartilage with mild to moderate cellularity.

The chondrocytes are in small clusters, with mild pleomorphic nuclei and minimal atypia noted. Chondroid chordoma and chondro sarcoma remains the subject of controversy. The immunohistochemical staining pattern
(Cytokeratin negative, epithelial membrane antigen negative) can be

helpful in distinguishing chondrosarcoma from chondroid chordoma. The only prognostic study published in 1993 estimated over all survival rates of $51 \%$ and $35 \%$ at 10 and 20 years respectively [16].

\section{Conclusion}

Chondroid chordoma is a controversial and confusing entity and possessing elements of both chordoma and cartilaginous tissue. Cartilaginous tumors share S-100 and vimentin immunopositivity with chordomas, but almost always lack the cytokeratin and EMA positivity, Chondrosarcoma of the skull base is a distinct clinicopathological entity. The immuno histochemical staining pattern (cytokertain negative, EMA negative can be helpful in distinguishing it from chordoma with chondroid differentiation (cytokeratin postive, EMA positive)

\section{Funding: Nil \\ Conflict of interest: Nil \\ Permission from IRB: Yes}

\section{References}

1. Chordoma review of clinico radiological features and features and factors affecting survival. Australas Radio 2001, $45: 427-434$.

2. Derome P. Spheno-ethmoidal tumors. Possibilities for exeresis and surgical repair. Neurochirurgie. 1972 May;18(1):Suppl 1:1-164

3. Huvos AG. Bone tumors. Diagnosis, treatment and prognosis. $2^{\text {nd }}$ edition. Philadelphia, Pa, USA: WB Saunders: 1991.

4. Volpe R, Mazabraud A. A Clinico pathologic review of 25 cases of chordoma (A pleomorphic and metastasizing neoplasm). Am J Surg Pathol. 1983 Mar;7(2):161-70.

5. Raffele C, Wright DC, Gutin PH, Wilson CB. Cranial chordomas : Clinical presentation and results of operative and radiation therapy in 26 patients. Neurosurgery. 1985 Nov;17(5):703-10.

6. Watkins LN, khudados ES, Kaleoglu M, Revesz T, sacres P, crockard HA. Skull base chordomas: a review of 38 patients, $1958-88$. British $\mathrm{Br} J$ Neurosurg. 1993;7(3):241-8.. 
7. Tan WS, Spigos D, khine N. chordoma of the sellar region. J Comput Assist Tomogr. 1982 Feb;6(1):154-8.

8. Falconer Ma, Bailey IC, Duchen LW. Surgical treatment of chordoma and chondroma of a skull base. J Neurosurg. 1968 Sep;29(3):261-75.

9. Heffelfinger MJ, Dahlin DC, Mac Carty CS, Beabout JW: chordomas and cartilaginous tumours at the skull base. Cancer. 1973 Aug;32(2):410-20.

10. Morita A, piergras DG: Tumors of the skull base in : vecht CJ ed. Hand book of clinical neurology, 68 revised series 24 neuro - oncology part II Amsterdam : Elsevier : 1997 :466.

11. RF, Melville GE, New PF, Austin - Seymour M, Munzwnrider J, pile - spellman J, snagnoli M, shoukimas GM. Momose KJ, carroll R, Davis KR : the role of MR and $\mathrm{CT}$ in evaluating clival chordomas and chondrosarcomas. AJR Am J Roentgenol. 1988

Sep;151(3):567-75.
12. W, ping $Z$ hao s, Hai xie $Z$, zhang $H$,zhanf J, yunxiao $\mathrm{J}$ : Endoscopic resection of chordomas in different clival regions Acta Otolaryngol. 2009 Jan;129(1):71-83.

13. Abenoza P, sibley RK, "chordoma an immunohistologic study. Hum Pathol. 1986 Jul;17(7):744-7.

14. Coindre JM, Rivel J, Trojani M, De Mascarel I, De Mascarel A. Immunohistological study in chordomas. J Pathol. 1986 Sep;150(1):61-3

15. Hirosawa RM, Santos AB, França MM, Fabris VE, Castro AV, Zanini MA, Nunes VS. Intrasellar chordroid chordoma ; a case report. ISRN Endocrinol. 2011;2011:259392.

16. Forsyth PA, Cascino TL, Shaw EG, Scheithauer BW, O'Fallon JR, Dozier JC, Piepgras DG. Intracranial chordomas a clinic pathological and prognostic study of 51 cases. J Neurosurg. 1993 May;78(5):741-7.

\section{How to cite this article?}

Rao BSS, Vissa shanthi, N Mohan Rao, Bhavna G, Swathi S, Murali Mohan K. Parasellar Chondroid Chordoma: a Case Report. Int J Med Res Rev 2014;2(5):507- 510. doi:10.17511/ijmrr.2014.i05.17 